\title{
Wheels of change in higher education
}

\section{A collaborative, multi-stakeholder project as a vehicle for sustainability education}

\author{
Kristin Warr Pedersen
Academic Division, University of Tasmania, Hobart, Australia \\ Kristin Warr Pedersen
Academic Division, University of Tasmania, Hobart, Australia \\ Emma Pharo \\ University of Tasmania, Hobart, Australia \\ School of Land and Food, University of Tas
Corey Peterson \\ Sustainability Team, Commercial Services and Development, \\ University of Tasmania, Hobart, Australia, and \\ Geoffrey Andrew Clark \\ School of Architecture and Design, University of Tasmania, \\ Launceston, Australia
}

\begin{abstract}
Purpose - The purpose of this paper is to profile the development of a bicycle parking hub at the University of Tasmania to illustrate how the Academic Operations Sustainability Integration Program promotes real change through the engagement of stakeholders from across an institution to deliver campus sustainability. This case study outlines one example of how place-based learning initiatives focused on campus sustainability challenges have delivered authentic education for sustainability in the Australasian higher education setting.

Design/methodology/approach - This case study outlines the process through which a cross-disciplinary place-based learning initiative was designed, implemented and evaluated over a three-year period. The evaluation of the project was designed to assess the impact of this education for sustainability approach on both operational and student learning outcomes, and to make recommendations on the continuation of place-based learning initiatives through the Academic Operations Sustainability Integration Program.

Findings - This case study illustrates how learning can be focused around finding solutions to real world problems through the active participation of staff and students as members of a learning community. This experience helped the authors to better understand how place-based learning initiatives can help deliver authentic education for sustainability and the success factors required for engaging staff and students in such efforts.

Originality/value - The case study highlights an example of an education for sustainability initiative that was mutually driven by the operational and learning objectives of an institution, and specifically the ways in which the engagement of staff and students from across an institution can lead to the successful integration of these two often disparate institutional goals.
\end{abstract}

Keywords Campus operations, Place-based learning, Sustainable transport, Authentic learning, Bike hub, Education for sustainability (EfS)

Paper type Case study

(C) Kristin Warr Pedersen, Emma Pharo, Corey Peterson and Geoffrey Andrew Clark. Published by Emerald Publishing Limited. This article is published under the Creative Commons Attribution (CC BY 3.0) licence. Anyone may reproduce, distribute, translate and create derivative works of this article (for both commercial and noncommercial purposes), subject to full attribution to the original publication and authors. The full terms of this licence may be seen at http://creativecommons.org/licences/by/3.0/legalcode
Received 27 October 2015

Revised 17 February 2016 Accepted 22 March 2016

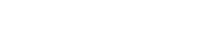


IJSHE

18,2

172

\section{Introduction}

There is growing recognition that human activity is placing strains on the capacity of the planet to support life, and transformative changes are needed to deliver better social, economic and environmental outcomes from communities around the world (Brown and Lambert, 2013; Hughes et al., 2013; van der Leeuw et al., 2012). Higher education institutions the world over are being implicated as both critical players and key stakeholders in engaging global debate and action to address the growing number of sustainability challenges we face. This imperative is exemplified by the United Nations Decade of Education for Sustainable Development (2005-2014), which encourages higher education institutions to "provide leadership by practicing what they teach through sustainable purchasing, investments and facilities that are integrated with teaching and learning” (UNESCO, 2006, np). In Australia, the government has committed the tertiary sector "to expand its work by achieving a culture of sustainability in which education for sustainability is reinforced by continuous improvement in the sustainability of campus management" (DEWHA, 2009, p. 21). Higher education institutions themselves are also making commitments to sustainability, through such actions as signing the Talloires Declaration, which is the pledge to incorporate sustainability into institutional operations and learning (University Leaders for a Sustainable Future, 1999).

Amongst necessary top-down approaches to incorporating sustainability into higher education, bottom-up approaches to education for sustainability are becoming increasingly prevalent (Barlett and Chase, 2004; Savelyeva and McKenna, 2011), and indeed many advocates are calling for a merger of these two approaches (Sterling et al., 2013; Scott et al., 2012). Furthermore, staff members are seen to play a critical role in initiating sustainability initiatives and coordinating these across institutions and campuses (Brinkhurst et al., 2011; Moore, 2005; Scott et al., 2012). Recognising the pivotal role that staff members play in leading sustainability initiatives in higher education institutions, this article highlights how, through collaboration and support, motivated staff can enhance the sustainability of a higher education institution and contribute to education for sustainability by influencing student and institutional learning outcomes. The role of dedicated, interdisciplinary and intra-organizational staff in addressing the knowledge-action gap in sustainability has been well presented by many authors (O'Brien, 2013; Courtenay-Hall and Rogers, 2002).

There are many excellent examples of tertiary learning, where teachers help students close the knowledge-action gap by exploring their own lives or their campus using sustainability ideas or tools (Barth et al., 2012; Rickards et al., 2015). This "place-based learning" approach enables a holistic learning experience, usually on their campus and the local environment, that links "heads" (knowledge) with "heart and hands" in a meaningful and practical way (Sipos et al., 2008).

Our project uses place-based learning and moves beyond students and academic teachers working together to include other important partners such as campus operations, local council, state government and cycling advocacy groups. The only other work in Australia that we know of that systematically includes stakeholders beyond teachers and students is the Australian National University's highly successful ANUGreen initiative, which includes campus operation staff along with teachers and students. Mcmillin and Dyball (2009) set the scene for our work by describing in detail why teaching sustainability through practice has been so effective at the Australian National University and end their paper by listing some of the projects that these students have been involved with (carbon footprint, greenhouse emissions accounting, recycling organics and offsetting travel).

The purpose of our article is to provide a detailed insight into how multi-stakeholder projects can work using a programme that integrates campus sustainability operations with 
in-class student learning activities and other stakeholders. The overarching programme is called the Academic Operations Sustainability Integration Program (AOSIP), and it has been recognised through a number of national awards in the Australasian sector as a leading example of a formalized place-based education programme in the higher education sector. In this article, we explain how AOSIP works through a case study of the design and development of an end-of-trip bicycle parking facility on the main campus of the University of Tasmania (UTAS).

This paper is also a response to Velazquez et al. (2005) who found that studies about sustainability on campus rarely mention what went wrong, which hampers learning. To that end, we present the difficulties as well as the aspects of the collaboration that were straightforward.

\section{The institution: University of Tasmania}

UTAS is the sole higher education provider on the Australian island state of Tasmania. By Australian standards, UTAS is classified as a medium-sized institution. Approximately 6,000 staff are employed, including operational, administrative and academic staff, some of whom are on research-only appointments. UTAS has a student population of nearly 30,000 , of which approximately 6,000 are international students. Both teaching and research are central foci at UTAS.

Teaching at UTAS tends to be siloed into different disciplinary schools (departments). Schools and degree programmes are established around traditional academic disciplines, such as chemistry, agricultural science, medicine, philosophy, geography and fine art. Until recently, sustainability, as a topic, was taught separately across a number of disciplines at UTAS. In 2014, an interdisciplinary "breadth unit" on sustainability was introduced as an elective available to all students across any degree area; however, this unit is offered as one of a suite of breadth units that students opt-in for based on personal interest or perception of how much the topic will contribute to the learning of their main discipline. While some schools stake more claim to sustainability as central to the content of their discipline area (e.g. environmental studies, geography, education and management), others identify sustainability as a topic with varying degrees of relevance to their field (e.g. plant science, social science and law). As such, the extent to which students at UTAS are exposed to sustainability as a concept or topic area relevant to their discipline varies greatly based on their enrolled degree. Furthermore, the extent to which students have opportunities to engage authentically with education for sustainability, as something that extends beyond a content laden "topic", into a more holistic pedagogical framework (Sterling, 2001) is even more variable and is primarily dependent on the epistemological position of the individual teachers they encounter. The recognition of education for sustainability as a holistic approach to learning and teaching is something that is understood by relatively few teaching staff at UTAS, and until recently, these individuals have carried out their work through the same isolated, siloed structure described above.

Historically, there has been a strong divide between learning and teaching policy and governance and the management of campus operations; however, the introduction of the Environmental Management Group in 2008 sought to bridge that gap. To advance UTAS sustainability initiatives, the Environmental Management Group - a volunteer-based group of interested academic and professional staff - developed the first ever Environmental Management Plan for UTAS, which called for the development of projects relevant to campus operations that could involve both academics and students, and could deliver sustainability outcomes across campus. In 2011, due to a shift to a more formalised governance structure of the group, the name was changed to the Environmental Management Committee. The Committee reported directly to
Wheels of change in higher education 
IJSHE

18,2

174

the University's Senior Management Team. The first initiative of this group was the appointment of several new staff positions developed as a "sustainability team", which worked in collaboration with the Environmental Management Committee.

Simultaneously in 2011, the UTAS Community of Practice Initiative was launched with the development of the institution-wide Education for Sustainability Community of Practice, a learning community comprising more than 60 staff members, from across the three main state-wide campuses. The community of practice was the first coordinated approach to education for sustainability at UTAS - aiming to bring together previously isolated staff working across the spectrum of sustainability. Enabling collaboration between a newly identified set of interdisciplinary colleagues, the community of practice has been successful at advancing the understanding of education for sustainability as a holistic pedagogic framework that requires integration of disciplinary and operational perspectives across the campus. The Academic Operations Sustainability Integration Program (AOSIP) is one of the key initiatives progressed by the community of practice.

\section{The Academic Operations Sustainability Integration Program (AOSIP)}

The AOSIP responds to calls for sustainability to be more thoroughly embedded in universities through the integration of research, service and teaching (Moore, 2005; Scott et al., 2012; ULSF, 1999). It aims to link teachers and university operations across all of the UTAS campuses. The AOSIP was developed by the sustainability team in Commercial Services and Development, a centrally positioned non-academic unit focusing on operational management of the University. In line with the UTAS Environmental Management Plan, the team identifies a set of "campus sustainability goals" that are used to engage disciplinary stakeholders in the design and implementation of campus-based sustainability projects. Through the AOSIP, students and staff engage in authentic learning activities (Lombardi, 2007) to learn about and interact with UTAS's infrastructure and operations in an effort to enhance institutional sustainability performance. In effect, university campuses become living laboratories.

The AOSIP enables teachers to deliver disciplinary content and learning activities through the example of a locally identified sustainability challenge. In doing so, the AOSIP aims to bring real world relevance into student learning initiatives by asking staff and students to contribute practical solutions to identified campus sustainability challenges. The end result is an approach to education for sustainability that is problem-based, allowing the integration of disciplinary learning to evolve as a response to an identified problem, rather than isolated disciplines driving sustainability from their own academic perspective (Pharo et al., 2014).

Prior to the commencement of AOSIP, there were very few deliberate connections drawn between student learning and the campus environment at UTAS. Some geography, plant science and agricultural science classes have used the University's 88-hectare eucalypt woodland estate behind the southern campus for fieldwork, and some postgraduate research projects have focused on environmental issues around campus. However, until the AOSIP was developed, none of this information was formally fed-back into institutional decision-making processes. Furthermore, no reported campus-based learning initiatives were specifically aimed at exploring or contributing to sustainability on campus. Prior to the AOSIP, education for sustainability at UTAS was more content focused and "the environment" and "community" were generalised to mean that which was outside of the campus.

Since 2011, the AOSIP has come to involve nine academic departments in a wide variety of projects from infrastructure design and delivery, to data gathering and risk assessments. All of the projects have involved both staff and students investigating campus operations, 
identifying sustainability issues, and proposing interventions and feeding this information to the Sustainability Committee and other decision-making bodies at UTAS.

\section{AOSIP case study: a campus "bike hub"}

This case study focuses on a specific AOSIP project that ran from 2010-2012, and involved more than 100 students and staff from the School of Geography and Environmental Studies and School of Architecture and Design, in a cross-disciplinary sustainable transport project. This project involved students in the research, advocacy, design and construction of a campus "bike hub" on the southern (largest) UTAS campus, in the state capital of Hobart. The bike hub is a facility that provides secure undercover parking for more than 45 bikes, 6 rentable lockers, a bike maintenance station, a water bottle filling station and 10 electric bike-charging stations powered by $2 \mathrm{~kW}$ photovoltaic solar panels.

The impetus for the bike-hub project was precipitated by a political and operational need to commence implementation of the relatively new UTAS Sustainable Transport Strategy. The strategy itself was the product of extensive consultation with UTAS as well as agencies responsible for transport planning and delivery, including city councils, state government and bus service providers. The sustainability team advocated for the bike-hub project because it promised to be a highly visible project that delivered on their sustainable transport goals, as well as mobilised and showcased the relatively new AOSIP. The bike hub itself involved multiple stakeholders, including:

- State government;

- Local council (Hobart City Council);

- Cycling lobby groups (Cycling South, Bicycle Tasmania); and

- University academic staff, students and operations staff.

Consultations with the UTAS Student Advisory Committee in 2010 revealed that bike transport on each of the state-wide campuses was hindered due to a lack of secure bike parking facilities available for student use. Distance between class locations and current bike parking options, bike thefts and having to leave bikes outside in wet weather were all described as reasons students chose other, less sustainable forms of transport to and from campus. Following these complaints about bike facilities, the sustainability manager saw value in this project with students as co-researchers and co-advocates for improving bike facilities on campus. The bike-hub project was designed to deliver on the Environmental Management Plan objective to involve students in campus sustainability initiatives while also providing students with education for sustainability, which would enhance their skills, their real-world experience and empower them with a sense of which contributing to change in their community (Brundiers et al., 2010; Cortese, 2003; Shephard, 2008).

To harness the support of senior management, operations and institutional policy-makers, it was necessary to frame this bike-transport project in terms of the identified advantages of the AOSIP approach. To do this, an intra-institutional memorandum of understanding $(\mathrm{MoU})$ was drawn up to clearly outline the mission and focus of AOSIP, the parameters of the bike-hub project and the value of the project for all participating parties. The MoU provided the framework for a project agreement that covered the budget, timelines and deliverables of the project, as well as the responsibilities and benefits for each party. It is worth noting, however, that beyond pragmatics the real value in the MoU process was in bringing operational and academic managers into dialogue about the integrated approach to education for sustainability being initiated by the AOSIP, and in essence raising awareness about this new holistic approach to sustainability on campus. It was through the MoU
Wheels of change in higher education 
IJSHE

18,2

176

process that the sustainability team began to meet and build networks with teaching academics from across the diverse schools and disciplines; therefore, a multidisciplinary and multi-stakeholder team was established that played a critical role in carrying this project through to fruition.

The bike-transport project collaboration started with the sustainability manager establishing a dialogue with teachers from the School of Geography and Environmental Studies and the School of Architecture and Design. The bike-hub project commenced in 2010 with 35 students from the School of Geography and Environmental Studies conducting transport counts by recording the number of people entering the campus, as well as identifying the different modes of transport (pedestrian, bicycle, bus, motorcycle, etc.) used at all six entry points of UTAS's southern campus. Transport counts were repeated in 2011 by a second group of students. Following the second round of data collection, two Masters students in Environmental Studies analysed the transport data, through which they were then able to determine optimal locations for a "bike-hub" facility on the southern UTAS campus. The sustainability team simultaneously conducted a survey on cycling behaviours of staff and students on the southern campus, the results of which were combined with the transport count analysis to help inform a group of architecture students to design, and with operational staff, build the hub. The architecture students were engaged across a number of elective units, and their involvement in the bike-hub project constituted 100 per cent of their assessment tasks in each participating unit.

The design and construction phase of the project involved students building prototypes of the lockers and other components of the bike hub, for which approval was sought from a panel of reviewers. The volunteer panel comprised university staff and representatives from cycling advocacy groups. The construction of the final product required a professional, competent and insured entity to be contracted by the University to take responsibility for the design and documentation of the work. The Launceston Assistance and Research Centre (LARC) was designated as the appropriate entity to undertake this work given their established role in working with architecture students - taking on a guidance and supervisory role, for not only the final product but also student learning.

Components of the bike hub were prefabricated at the School of Architecture and Design, and under the direction of Commercial Services and Development staff, they were then installed on the southern campus in 2012. The final promotion and communication phase of the bike-hub project was undertaken as part of an undergraduate student project in the School of Geography and Environmental Studies. Students developed a communication strategy outlining the benefits of sustainable transport to staff and students on campus. This involved collecting additional transport data and writing speeches and a brochure about the benefits of sustainable transport for presentation to the UTAS Vice-Chancellor and the Tasmanian Government's Minister for Sustainable Transport at the official opening of the bike hub in October 2012. A student from the School of Journalism then prepared the draft press release for the UTAS Media Office, as the final step in the bike-hub project.

\section{Participant evaluation}

From an operational perspective, the bike-hub project delivered on all three objectives of the UTAS Sustainable Transport Strategy, which requires efforts that:

(1) maximize access to the University by healthy and sustainable transport options;

(2) reduce the incidence of single occupant vehicle use and unnecessary travel; and

(3) reduce greenhouse gas emissions from the University transport sources. 
More specifically, the project provided enhanced bicycling infrastructure to the southern campus, increased the safety of bicycling and pedestrian routes at the campus, encouraged a different modal choice for transport to the campus and thus helped lower the collective UTAS carbon footprint from transport. To investigate the learning outcomes of this project, formal and informal feedback was sought from students, peers and industry. Formal feedback was collected through our University's end of semester student evaluations of teaching and learning - a survey sent to students at the end of each teaching semester. Students answered a series of questions using a Likert scale (strongly agree, agree, neutral, disagree, strongly disagree and not applicable). Additional feedback was solicited from students and industry through email surveys. The staff was interviewed and participants were asked to write a reflection on their experiences via an email to one of the authors. The data collection was approved by the University's Social Science Human Research Ethics Committee (Ethics reference number H0011876).

Students in both geography and architecture reported positively on their experience with the bike-hub project by selecting "agree" or "strongly agree" in surveys. They used the open comments section of the survey to give more detailed feedback and mention points not covered by the formal questions. All architecture students and 95 per cent of geography students said that due to their participation in these activities, they were motivated to achieve the learning outcomes specified for their class. All architecture students and 90 per cent of geography students said that the learning experiences in their class had helped them to achieve the stated learning outcomes of the activity.

For architecture students, the intended and achieved learning outcomes were to:

- develop and enhance their design skills by incorporating first hand office experiences in design, documentation and construction;

- critically reflect on learning experiences; and

- operate in a professional manner through the development of skills in project management and administration.

For geography and environmental studies students, the intended and achieved learning outcomes were to:

- communicate information about climate-change adaptation to a broad audience;

- develop communication materials for a community client; and

- reflect on their experiences with their client and the extent to which their experiences matched their expectations.

In open-ended evaluation comments from 2010 and 2011, architecture students noted the most helpful aspect of the activity was the "hands-on nature of the course and the realistic accountability of the project" and "real-life scenarios and integration with architects". They commented that there needed to be more of this type of task in university learning because it included the complexity of a real-life project, including dealing with budgets, ethics, design, clients, tasks and the various problems associated with real-life tasks of being an architect.

In the student evaluation comments from 2010, geography students noted that the most helpful aspect of the activity was "to be able to apply some of our learning to the wider community"; the "integration with other academics and professionals"; and "the many open discussions which are based on an open and flexible university organization". An example of a more descriptive comment provided by a student:

I really enjoyed being part of the bike-hub project. Although we were not involved in setting up the initiative, it was great to gain experience in the practicalities of making something like this go ahead
Wheels of change in higher education 
IJSHE

18,2

178 (i.e. movement counts, research, surveying). In this case, I think it was important to have students involved to encourage a sense of ownership and appreciation of the new resource. Also, I enjoyed being a part of the project because I find it very exciting when the work I do in class can help to have an impact in the real world.

My involvement with the UTAS Bike Hub has allowed me to apply class lessons to a real world setting by critically evaluating approaches to maintain social and ecological resilience in the face of climate change.

The journalism student and the environmental management students were not assessed formally and were motivated to take part to add to their work experience, rather than being compelled to participate as part of formal assessment. We have no formal student evaluation results from these students; however, continued communication with the journalism student revealed that she was "delighted" to get a published story in a major newspaper as well as an item on the television news. As a bonus, she made some valuable connections with professional media staff through the University's media unit, who control all the press releases from the University.

While the authors would like to be able to follow-up with participating students on whether this activity has helped them in their graduate lives, we have no immediate plans to undertake that work. This is partly due to the difficulty in attributing a skill that was useful in the workplace to a relatively small activity conducted years before and undertaken just once in their degree. However, we continue to monitor the immediate outcomes and reflections of students as a result of their participation in AOSIP activities, and have a small collection of anecdotal data through personal emails of the positive impact of the programme on the graduate experience.

To determine whether the bike parking hub is helping shift people onto bikes for their transport to and from university, the authors continue to count the numbers of pedestrians, bike riders, motorcyclist and bus passengers on an annual basis. Those results are presented in a separate paper under development that specifically focuses on modal shift. However, we can report here that there has been a measureable increase in the number of people riding a bike to campus despite little improvement to the safety of city streets en route to campus.

External stakeholders were also very positive about the achievements of the students and staff who participated in this project. We received ongoing positive feedback from the peak bicycle advocacy group, Bicycle Tasmania, and the local government bicycle facilities coordinator. The Minister for Sustainable Transport, in opening the bike hub, stated that:

UTAS is to be commended for planning for the future, with a focus on sustainability, and the result is fantastic. This bike hub is an example of how these challenges can be turned into opportunities, where infrastructure is more people focused and getting from one location to another is a pleasurable experience. This hub is also an inspiring example of students and staff working together, with the State Government and Hobart City Council (UTAS, 2012).

A number of unexpected outcomes of the project included the recognition the programme received as a result of the bike hub. The University's Vice-Chancellor congratulated the work at the public opening, stating that: "This facility is a product of our students' dedication and passion for environmental sustainability. I extend my thanks to them and to the staff who have supported this project" (UTAS, 2012). One month later in the internal University newspaper, the Vice-Chancellor further stated that: "Bike hubs across UTAS show how our teaching and research programmes can be integrated with our organisational philosophy" (Rathjen, 2012, p. 2). 
The bike-hub project has been highly regarded by peers within the University and from across the Australasian education sector. The project was one of a suite of AOSIP projects that together saw UTAS win the national 2012 Australasian Campuses Towards Sustainability Award of Excellence based on a poll of peer institutions in Australia and New Zealand. The AOSIP was then recognised with a National Office for Learning and Teaching award for Programs that Enhance Learning in 2015. The project also won the Cycling Promotion Fund's Australian Bicycling Achievement Award in March 2013 and an internal Vice-Chancellor's Teaching Award for Programs that Enhance Learning in 2013.

\section{Challenges to achieving operational sustainability}

Despite high-level recognition of the work of the sustainability team, there are ongoing challenges to ensuring funding for the AOSIP. Funding cuts to the Australian tertiary sector have resulted in universities needing to rationalize expenditure and focus on key strengths, with particular attention to those that bring money into the institution or deliver cost savings. These budget cuts are a significant challenge to securing funding for the on-ground sustainability works that are central to the AOSIP model. While AOSIP has the potential to save and generate funding, the bike-hub project prioritized student learning and experience over cost savings. An "off the shelf" bike hub could have been purchased for a similar amount and the location for it could have been chosen from anecdotal evidence. While being relatively cost-neutral, the additional "cost" in making this an AOSIP project was to take a project that operational staff would have completed in 6-9 months without student involvement to one that took nearly two years with attendant operational staff time costs. The added time reflected academic schedules and the need to demonstrate and undertake the entire decision-making process within this constraint. To some, this has unfortunately highlighted an example of a student-centred activity that slowed down a delivery schedule, which may challenge the sustainability team in making a case for similar types of AOSIP projects.

While it is necessary to recognise and celebrate the efforts of the staff and students involved in the bike-hub project, it is also important to note that the project is not sustainable in its own right. The project was resource intensive in terms of staffing and required long project timelines. With its focus on the construction of bike hubs, the project is also limited in terms of geographic expansion and interdisciplinary reach. While the plan is for eight major bike hubs to be constructed across all campuses in the next four years, the financial, geographic and pedagogic limitations of such a project make this a finite focus for the AOSIP. Therefore, the ongoing challenge at UTAS is to continue to build on the success of the bike-hub project through ongoing support of the AOSIP model. Support is needed to ensure the delivery of other sustainability campus projects in the future (Mcmillin and Dyball, 2009). The process of integrating operations with learning and teaching needs continued commitment and proactivity from managers and staff is needed if education for sustainability is truly to be embedded as a holistic pedagogy and practice at UTAS.

The biggest challenge to the sustainability of the AOSIP model is in ensuring ongoing support for the sustainability team to work in partnership with staff responsible for academic programmes at UTAS. While the networking capacity of the sustainability team is extensive in terms of their motivation and capabilities to build partnerships, the team often has to justify why they choose to "deploy" their work to academic staff and students across the institution. Traditional approaches to dividing campus operations from student learning activities continue to challenge the team, as they struggle to shift our institutional culture towards a more holistic understanding of education for sustainability.
Wheels of change in higher education 
IJSHE

18,2

180

The relatively small sustainability team of 2.7 staff (at full time equivalent) has a broad range of responsibilities, including the need to address a number of on-campus sustainability challenges across a suite of initiatives and focus areas. To achieve this, a number of projects in addition to the bike-hub project have been allocated to the AOSIP, including exploring renewable energy options, building eco-efficiency studies, a peak oil risk assessment, a sea level rise risk assessment for university facilities, carbon management, waste auditing, biodiversity studies and land management, as well as promotional activities. These have drawn on the work of staff and students from the disciplines of engineering, business, geography, agriculture, architecture and urban design. To date, however, these initiatives have relied on the existing networks of the sustainability team. Therefore, a key challenge is to engage senior managers to recognise the need for the sustainability team to continue to build working relationships with staff and students from across the broad range of academic programmes at UTAS. The project was also more work than normal for the academic staff that are under time and financial pressure to take easier options for assessment than a complex, collaborative "real" project.

One of the key successes of the AOSIP has been overcoming previously identified barriers to interdisciplinary teaching at UTAS, including the siloed nature of curriculum and funding and insufficient resources to support staff in central coordination positions (Pharo et al., 2012). The leadership provided for the AOSIP by the centrally located (and non-academic) sustainability team has been central to the success of this approach. It is through this central leadership that the AOSIP has been able to ground education for sustainability at UTAS in real-world challenges, enabling interdisciplinary academics to blur the boundaries of the disciplines and work together to address local challenges. As such, the sustainability team has been able to impact positively on student learning, while highlighting that sustainability challenges on campus are a collective responsibility of all staff and students.

While the sustainability team has often been forced to justify why they network with the academic side of the University, it is exactly these partnerships that have led to the success of the AOSIP in delivering both operational and academic outcomes for sustainability. Continued funding and support of this integrated facilitation of the AOSIP is central to the success of the programme and UTAS's efforts to support and enable authentic education for sustainability.

\section{Solutions and recommendations}

Through governance and policy commitments such as the UTAS Environmental Management Plan and the signing of the Talloires Declaration and a Sustainability Policy, UTAS has committed to ensuring its operations as well as its research and teaching are directed towards sustainable outcomes. However, the challenge to follow through on this commitment will require broad institutional support and a cultural shift towards re-conceptualizing education for sustainability as a holistic, whole-of-institution approach. This case study reiterates the findings of numerous other studies that highlight the critical role played by a centrally located staff leader for identifying, integrating and achieving sustainability outcomes (Barlett, 2004; Brinkhurst et al., 2011; Norgaard, 2004; Jahiel and Harper, 2004). Based on the challenges of securing continued funding and support of the AOSIP as a truly integrative programme, the ongoing employment of staff whose job is specifically to integrate sustainability initiatives with learning, teaching and research on campus is critical to the success of such an initiative.

Our case study also unexpectedly highlighted the usefulness of involving influential people in inspiring change, a recommendation in line with the change management literature (Gill, 2002; Gilly et al., 2008). The bike hub was useful in raising the profile of education for 
sustainability through the official launch, where the State Minister for Sustainable Transport and the Vice-Chancellor of the University both rode electric bikes and spoke in glowing terms about the beautiful, functional bike hub and the staff and students who made it happen in spite of many hiccups. The concrete (plus wood and steel!) achievement of the collaboration has helped these two senior figures think of the University as a proactive collaborator that is capable of driving sustainability education. This has led to continued collaborations that have contributed to the state becoming a United Nations Regional Centre of Expertise in Education for Sustainable Development (2015).

\section{Future research directions}

This case study highlights that students are highly motivated to engage in real-life experiences they can visibly link to their learning. However, there is more work to be done to document student outcomes in both the short and long term. For example, it would be of great benefit to evaluate whether and to what impact students thought that their AOSIP involvement was useful in their working life. It could be that the activity helped make their studies more engaging without providing much in the way of skills or networks that were useful once they finished their studies. It could also be that such projects do deliver the authentic assessment opportunities that build the skills often identified by employers as lacking from a purely theoretical educational experience. This follow-up information would be difficult to collect but would be possible with the involvement of enough students and careful tracking of their contact details on leaving the University.

The key role of the sustainability manager and other campus operations staff in the AOSIP cannot be overstated. The manager provided the central leadership that guided this collaborative project and integrated it into various agendas and university goals. The sustainability manager was important in a practical sense in undertaking the purchase and works orders needed to construct the facility, as well as negotiating the funding and supervising the site works. The manager was also important in being able to harness different staff and student cohorts over a long period of time, with each group filling a particular role in this long-term project. It is important to remember that the manager's role was only viable because the academic staff and students provided the person-power to get things done. Some social network analysis would be interesting to formally document the many stakeholders, their relationships and the degree to which they interact. These constructed networks have been shown to be more powerful than formal structures in terms of achieving real outcomes (Serrat, 2009). Complimentary research into the most efficient strategies to activate and maintain these networks would also be of value.

\section{Conclusions}

The Australian higher education sector is attempting to build resilience to what seems to be a string of budget cuts from the federal government. Simultaneously institutions continue to commit to global and national initiatives to work towards a more sustainable future. In such an unpredictable and stretched climate, programmes like the AOSIP emerge as potential vehicles through which economic, environmental and educational goals can be met. As is often the case, it is sometimes hard for people to "see the forest through the trees", and there is a significant amount of work to be done before activities such as those described in this article are recognised as core business of the University.

This case study has highlighted how the UTAS's Academic Operations Sustainability Integration Program (AOSIP) helped a multidisciplinary team of professionals, students, academics, industry, not-for-profits, state government and local council officials, to collaborate on a project to enhance sustainable transport to the largest University campus in the state of Tasmania, Australia. Through the design, development and advocacy of a
Wheels of change in higher education 
IJSHE

18,2

182

bike-hub project, AOSIP fostered connections between academics and professional staff and used this collaborative network to situate the University as a living laboratory of teaching and learning. The project adapted to take advantage of the people and resources that were available to eventually build a facility that is well used and of which the University is proud.

The sustainability team that established and managed the AOSIP has made significant progress in meeting operational goals for sustainability and has thus been the critical element in UTAS successes at achieving its national and international commitments to work towards a sustainable future. Additionally, through involvement in an institution-wide Community of Practice for education for sustainability, the sustainability team has been able to ensure that learning is embedded in the UTAS operational approach to sustainability. The potential of the AOSIP model to continue to integrate learning and teaching with campus operations is only as limited as the support such an initiative receives from senior managers, teachers and academics from across the disciplines. It is our hope, and our aim, that this support is maintained and that the acknowledgement and celebration of the AOSIP, as a model of education for sustainability's best practice, continues into the future.

\section{Acknowledgments}

The authors would like to extend special thanks to Anna Lyth who authored the Sustainable Transport Strategy and supervised the student work on the movement analyses. Thanks also to the team within Commercial Services and Development and in particular to our senior operational staff Matt Smith and Jacinta Young for supporting the enabling framework as first developed by Kamal Singh, the University's previous sustainability manager. Thank you to Joan Rodrigues for overseeing the contracting details; Ken Steele for managing the site construction works; Mark White for assiduously working out the electrical connections required for the photovoltaic panels, LED lighting and e-bike charging stations; Graham Lord and Tom Beattie for swiftly completing the landscaping in time for the official launch; Heather Knibbs for organizing the locker hiring scheme; and Rowena Zwart as the all-rounder sustainability officer that helped fill in the student data collection roster gaps. Special thank you also to Christie Denman, Architect from the Launceston Assistance and Research Centre (LARC) who worked with students from the School of Architecture and Design on the delivery of this project.

\section{References}

Barlett, P.F. (2004), "No longer waiting for someone else to do it: a tale of reluctant leadership", in Barlett, P.F and Chase, G.W. (Eds), Sustainability on Campus: Stories and Strategies for Change, The MIT Press, Cambridge, MA, pp. 67-90.

Barlett, P.F. and Chase, G.W. (2004), Sustainability on Campus: Stories and Strategies for Change, The MIT Press, Cambridge, MA.

Barth, M., Fischer, D., Michelsen, G., Nemnich, C. and Rode, H. (2012), “Tackling the knowledge-action gap in sustainable consumption: insights from a participatory school programme", Journal of Education for Sustainable Development, Vol. 6 No. 2, pp. 301-312.

Brinkhurst, M., Rose, P., Maurice, G. and Ackerman, J.D. (2011), “Achieving campus sustainability: top-down, bottom-up, or neither?", International Iournal of Sustainabilitv in Higher Education, Vol. 12 No. 4, pp. 338-354.

Brown, V.A. and Lambert, J.A. (2013), Collective Learning for Transformational Change: A Guide to Collaborative Action, Routledge, New York, NY.

Brundiers, K., Wiek, A. and Redman, C.L. (2010), "Real-world learning opportunities in sustainability: from classroom into the real world”, International Iournal of Sustainability in Higher Education, Vol. 11 No. 4, pp. 308-324. 
Cortese, A.D. (2003), “The critical role of higher education in creating a sustainable future”, Planning for Higher Education, Vol. 31 No. 3, pp. 15-22.

Courtenay-Hall, P. and Rogers, L. (2002), "Gaps in mind: problems in environmental knowledge-behaviour modelling research", Environmental Education Research, Vol. 8 No. 3, pp. 283-297.

Department of the Environment, Water, Heritage and the Arts (DEWHA) (2009), Living Sustainably: The Australian Government's National Action Plan for Education for Sustainability, Commonwealth of Australia, Canberra, ACT.

Wheels of change in higher education

Gill, R. (2002), “Change management or change leadership?", Lournal of Change Management, Vol. 3 No. 4, pp. 307-318.

Gilly, A., Dixon, P. and Gilly, J.W. (2008), "Characteristics of leadership effectiveness: implementing change and driving innovation in organizations", Human Resource Development Quarterlv, Vol. 19 No. 2, pp. 153-169.

Hughes, T.P., Carpenter, S., Rockström, J., Scheffer, M. and Walker, B. (2013), "Multiscale regime shifts and planetary boundaries", Trends in Ecology \& Evolution, Vol. 28 No. 7, pp. 389-395.

Jahiel, A.R. and Harper, R.G. (2004), "The Green Task force: facing the challenges to environmental stewardship at a small liberal arts college", in Barlett, P.F and Chase, G.W. (Eds), Sustainability on Campus: Stories and Strategies for Change, The MIT Press, Cambridge, MA, pp. 49-66.

Lombardi, M. (2007), "Authentic learning for the 21st century: an overview”, EduCause Learning Initiative, ELI Paper, Vol. 1.

Mcmillin, J. and Dyball, R. (2009), "Developing a whole-of-university approach to educating for sustainability linking curriculum, research and sustainable campus operations", Iournal of Education for Sustainable Development, Vol. 3 No. 1, pp. 55-64.

Moore, J. (2005), "Seven recommendations for creating sustainability education at the university level: a guide for change agents", International Journal of Sustainability In Higher Education, Vol. 6 No. 4, pp. 326-339.

Norgaard, R.B. (2004), "Transdisciplinary shared learning”, in Barlett, P.F and Chase, G.W. (Eds), Sustainability on Campus: Stories and Strategies for Change, The MIT Press, Cambridge, MA, pp. 107-120.

O’Brien, K. (2013), “Global environmental change III: closing the gap between knowledge and action”, Progress in Human Geography, Vol. 37 No. 4, pp. 587-596.

Pharo, E.J., Davison, A., Warr, K., Nursey-Bray, M., Beswick, K., Wapstra, E. and Jones, C. (2012), "Can teacher collaboration overcome barriers to interdisciplinary learning in a disciplinary university? A case study using climate change", Teaching in Higher Education, Vol. 17 No. 5, pp. 497-507.

Pharo, E., Davison, A., McGregor, H.V., Warr, K. and Brown, P. (2014), "Using communities of practice to enhance interdisciplinary teaching: lessons from four Australian institutions", Higher Education Research and Development, Vol. 22 No. 2, pp. 341-354.

Rathjen, P. (2012), "Message from the vice-chancellor", UNITAS News.

Rickards, S., Howitt, R. and Suchet-Pearson, S. (2015), "Ecological footprinting as a top-down and bottom-up approach to complete campus engagement and transformation towards the One Planet Goal", in Filho, W.L., Brandli, L., Kuznetsova, O. and Finisterra do Paco, A.M. (Eds), Integrative Approaches to Sustainable Development at University Level, Springer International Publishing, pp. 43-66.

Savelyeva, T. and McKenna, J.R. (2011), "Campus sustainability: emerging curricula models in higher education", International Journal of Sustainability in Higher Education, Vol. 12 No. 1, pp. 55-66.

Scott, G., Tilbury, D., Sharp, L. and Deane, E. (2012), "Turnaround leadership for sustainability in higher education", Final report for the Australian Government Office for Learning and Teaching, Commonwealth of Australia, Sydney. 
IJSHE

18,2

184

Serrat, O. (2009), "Social network analysis", available at: http://igitalcommons.ilr.cornell.edu/intl/206/

Shephard, K. (2008), "Higher education for sustainability: seeking affective learning outcomes", International Journal of Sustainability in Higher Education, Vol. 9 No. 1, pp. 87-98.

Sipos, Y., Battisti, B. and Grimm, K. (2008), "Achieving transformative sustainability learning: engaging head, hands and heart", International Journal of Sustainability in Higher Education, Vol. 9 No. 1, pp. 68-86.

Sterling, S. (2001), "Sustainable education: re-visioning learning and change", Schumacher Society Briefing No. 6, Green Books, Dartington.

Sterling, S., Maxey, L. and Luna, H. (Eds) (2013), The Sustainable University: Progress and Prospects, Routledge, New York, NY.

UNESCO (2006), Framework for the UNDESD International Implementation Scheme, UNESCO, Paris.

University Leaders for a Sustainable Future (ULSF) (1999), The Talloires Declaration, University Leaders for a Sustainable Future, Washington, DC.

UTAS (2012). Public launch speeches by the Honorable Nick McKim and Professor Peter Rathjen of the University of Tasmania. Sandy Bay Campus, 10 October 2012.

van der Leeuw, S., Wiek, A., Harlow, J. and Buizer, J. (2012), "How much time do we have? Urgency and rhetoric in sustainability science", Sustainability Science, Vol. 7, pp. 115-120.

Velazquez, L., Munguia, N. and Sanchez, M. (2005), "Deterring sustainability in higher education institutions: an appraisal of the factors which influence sustainability in higher education institutions", International Iournal of Sustainability in Higher Education, Vol. 6 No. 4, pp. 383-391.

\section{Further reading}

Corcoran, P.B. and Wals, A.E.J. (Eds). (2004), Higher Education and the Challenge of Sustainability: Problematics, Promise and Practice, Kluwer Academic Publishers, New York, NY.

Cox, M.D. (2004), "Introduction to faculty learning communities", New Directions for Teaching and Learning, No. 97, pp. 5-23.

Ferreira, J.L. and Tilbury, D. (2012), "Higher education and sustainability in Australia: transforming experiences", Higher Education in the World 4, Higher Education's Commitment to Sustainability: from Understanding to Action, Palgrave Macmillan, pp. 96-99.

\footnotetext{
About the authors

Kristin Warr Pedersen has worked as an academic in the AOSIP and participated in the design of the programme through coordination of the institutional Communities of Practice Initiative. Kristin Warr Pedersen is the corresponding author and can be contacted at: Kristin.Warr@utas.edu.au

Emma Pharo is an academic member of the AOSIP whose students have worked on the research, design, construction and promotion of the bike hub.

Corey Peterson is the sustainability manager at the University of Tasmania and the designer of the Academic Operations Sustainability Integration Program.

Geoffrey Andrew Clark is an academic member of the Program whose students have worked on the research, design, construction and promotion of the bike hub.
}

For instructions on how to order reprints of this article, please visit our website:

www.emeraldgrouppublishing.com/licensing/reprints.htm

Or contact us for further details: permissions@emeraldinsight.com 